Journal of Social Sciences 4 (2): 140-145, 2008

ISSN 1549-3652

(C) 2008 Science Publications

\title{
A Philosophical Analysis of the Challenges of Science and Technology in Contemporary Africa: The Nigerian Experiment
}

\author{
Akinnawonu Benson Monehin \\ Department of Philosophy, Adekunle Ajasin University, Akungba Akoko, Ondo State, Nigeria
}

\begin{abstract}
Science and technology engendered unexpected social, political and health related problems. These included corrupt and dubious utilization of information and communication technology, environmental pollution and protection and depletion of the ozone layer which endangered human health. This sstudy examined the positive and negative implications of science and technology in Africa using Nigeria as a case study. This attempt became germane owing to the important place of the scientific and technological enterprise in the entire pattern of human life. The critical and conceptual methods of analysis were employed and the available literatures on the problem provided the background for the study. The study showed the dangers in uncontrolled destructive character of scientific and technological knowledge to human survival and suggested appropriate control measures. The study, therefore, suggested resource control, the control of chemical and biological weapons and the abuse of information and communication technology. Manufacturers of various technologies needed to create subsidiary technology and put in place necessary mechanisms for curtailing the foreseeable consequences of their products. Indeed, technological civilization should not be blindly embraced.
\end{abstract}

Key words: science, technology, philosophical, challenges

\section{INTRODUCTION}

Science is undoubtedly one of the mainstays of modern civilization. This view is not unconnected with the fact that scientific discoveries had touched the lives of almost all people living today. Science is admired in view of its countless accomplishments in medicine, engineering, communication and other disciplines, through which the quality of life had improved. Science and technology are exceptionally powerful forces materially conditioning both humans and the nature of their government, which often lead to a general reassessment of national priorities. However, it has been observed that science and technology also involve some risk taking. They are viewed with a mixture of admiration and fear, hope and despair, the source and cure of many of the ills of modern industrial society ${ }^{[1]}$.

Advancement in technology often had tragic implications for mankind, leading to possible mass destruction. Environmental issues such as global warming, depletion of ozone layer and radiation exposure are expected to be given due public attention. The toxic substance released to the atmosphere as a form of industrial waste punctures the ozone layer which in turn reduces its capacity to resist some unwanted or dangerous substances that are capable of causing diseases of different sorts. It is not enough to dispel fears about ozone depletion and global warming on the pages of newspapers. These known scientific disasters cannot just be glossed over. Scientists and technologists must account for them if life must continue on the surface of the earth.

Nigeria/UNESCO project for the reform and revitalisation of Nigeria's science, technology and innovation system was officially launched in 2005 .

UNESCO agrees to develop a special programme to revitalise the country's science and technology and innovation system. To this end, a stakeholders' sensitization workshop preparatory to baseline survey of Nigeria's National Science, Technology and Innovation (ST and I) system was held between 18th February and 3rd March $2008^{[2]}$. The sensitization workshop among other things did not address the following pressing issues. There is the contention that electromagnetic fields are harmful to human and animal health. There is extensive pollution of our environment due to high voltage power lines. Even, it is believed that the personal computer and the microwave oven in peoples home are other sources. The cellular telephones are also capable of damaging user's brain leading to health risks such as cancer and death ${ }^{[1]}$. This same source disclosed that a British electricity authority was sued over the death of a boy who allegedly developed cancer as he slept near high voltage power cables. This 
calls for serious concern as many people in Nigeria now erect their residential buildings along high voltage power lines in utter disregard to Town Planning regulations.

Background to science and technology: Technology is as old as mankind. The great philosopher, Francis Bacon, conceives of experimental science as a means of enlarging man's dominion over nature. The significance of Bacon's assertion is the encouragement given to scientists in pursuing their investigations toward improving the lots of mankind. In the same vein, technology also evolves new apparatus, tools and machines, which aid scientists in achieving useful insights into the natural world.

Russell understands science as the attainment of the kind of knowledge which establishes general laws governing a number of particular, isolated facts ${ }^{[3]}$. This had assisted man's power and technique of controlling and manipulating nature. According to Nagel, science emerges owing to the inability of primitive value and beliefs to cope with the challenges of existence ${ }^{[4]}$. Morgan defines technology as an activity resulting in procedures for building and creating things (or services) in prototypes and modes of products, in gadgets and inventions ${ }^{[5]}$.

In his own considered view, Smith maintains that:

Technology embraces a variety of practical activities that provide goods and services for man's use, enjoyments, welfare, manufacturing, transportation, communication, the raising and processing of food and the conversion of energy into usable forms are typical 20th century technology activities especially as they involve the application of scientific understanding of natural phenomena that are complex, highly skilled and technical in operation ${ }^{[6]}$.

The above conceptions of technology show that technology is an attempt by man in applying the theories and principles of science in controlling the physical world. This is partly why Fadahunsi conceives of technology as methodical utilization of natural resources and forces on the basis of the knowledge of nature in order to take care of man's needs ${ }^{[7]}$.

Onuobia gives a two-way interpretation of technology. In the first place, it refers to the tools and artefacts which men use in daily activities to manipulate nature and their environment for their benefit. The second perspective sees technology as the study of these artefacts, tools, machines themselves ${ }^{[8]}$. Asimor describes technology as the means or activity by which man seeks to change or manipulate his environment ${ }^{[9]}$.

The various conceptions of science and technology suggest that the two concepts are closely related. While science deals with the exploration, description, explanation and prediction of occurrences that take place in the world, technology on the other hand is the practical manifestation or direct application of scientific knowledge, which enlarges man's physical and intellectual powers. Technology can, therefore, be defined as the conscious application of man's knowledge for productive activity for the purpose of satisfying man's pressing needs which include alleviation of poverty, control over natural disasters, making the natural environment conducive for living and, most importantly, ensuring diseases' control.

\section{RESULTS}

- Disastrous environmental issues such as extensive pollution of our environment due to chemical and industrial wastes, the damaging effect of the microwave oven, cellular telephones on the user's brain, global warming and depletion of ozone layer and radiation exposure deserve due public attention

- The on-going crises in the Niger-Delta are as a result of Government's high level of insensitivity to the dangers caused by oil exploration in the region

- The banks and many business organisations operating on-line business in Nigeria are prone to fraudsters owing to erosion of privacy in their accounts

- There is serious abuse of internet browsing and access by mostly the youths in Nigeria which raises moral and legal issues

\section{DISCUSSION}

The rising trend in technological advancement is posing serious challenges to mankind and the natural environment. This becomes worrisome owing to the fact that technology is no longer solely meant for the betterment of mankind but also noted for its destructive and damaging effects. That is, it has great moral, economic, social and political implications.

Goldsmith captures this observation vividly when he asserts that:

Advances in science and technology seem to have escaped our control and they are regarded as acting not only independently of us, even against our will. In philosophical terms, we are 
witnessing the alienation of science and technology from culture generally ${ }^{[10]}$

No wonder, Ali affirms that technology in spite of its overwhelming positive impacts on man and society appears to lag behind in the sphere of rationality and philosophical foundations. He further contends that:

.... we need also a theory of praxis and an epistemology of technology. Technology as right method in the act of making, as a production- activity, is in need of philosophy, as its judge, its critique, its support, its complement, its guide and its director ${ }^{11]}$.

The above remark by Ali represents a suggestion to the effect that technology has to be regulated or put under rational control if it is to serve human interest. Bryan argues that one of the general requirements of sustaining scientific and technological activity in traditional societies is the availability of economic surplus to patronize a scientific stratum. It is this that will provide the structural conditions for sustained intellectual activity ${ }^{[12]}$. This study, as a child of necessity, represents an attempt to appraise the impacts of science and technology with the aim of determining the needed measure of control that will elicit the desired effects of our growing technology in the $21^{\text {st }}$ century. Hence, the goal of science and technology is the rational interpretation and application of the facts of existence as disclosed by human faculties and senses ${ }^{[13]}$.

There are identifiable positive impacts of technology on mankind. These include improved communication. For instance, the introduction of General System of Mobile telecommunications (GSM) in Nigeria by the Obasanjo Administration (19992007), the use of Asynchronous Transfer Mode (ATM) machine in Banking sub-sector of the Nigerian economy for the purpose of gaining high speed access to the internet for their clients-a network protocol that transmits data in small packet of a fixed size connecting two or more local area networks at a speed of $155 \mathrm{mbps}$ and higher. The ATM is beneficial as it had reduced the usual long queue in the various banks and customers now have un-interrupted access to their account even including weekends.

Olaolu Mabol identifies improved transportation networks, development in health service delivery through the discovery of modern medical apparatuses and gadgets, which aid improved health care delivery ${ }^{[14]}$. A very good example is Kanu Heart Foundation, Lagos, Nigeria which now makes it possible for patients with heart related problems to have access to quick surgical attention without facing the problem of how to get them out of the country for medical treatment. This saves time and money. In the past, a lot of lives had been lost due to poverty and lack of ready access to medical facilities of such nature.

Technology had also made significant impact on politics and economy of nations of the world. For instance, the invention of sophisticated chemical weapons enhances the security consciousness of nations, various security agencies such as the Police Force, Military and other private security outfits in Nigeria are now capable of providing adequate security as a result of provision of the state of the art facilities anchored on Information and Communication Technology (ICT). Consequently, both international and national boundaries are being monitored via satellite. Series of surveillance cameras are also being mounted at different locations to enable them monitor vices and sharp practises. The case in mind is the application of this technology during the 2007 gubernatorial election in Ekiti State, Nigeria, where the Action Congress (AC) candidate installed cam-coders to cover elections. The visual tape-recorded was later presented at an Election Petition Tribunal as evidence of election malpractices and manipulations. This is a new innovation as a result of the development of science and technology.

In his own considered view, Fadahunsi affirms, science through its contribution to understanding liberates people from many forms of ignorance and superstition. Technology liberates them from many physical constraints and insecurities ${ }^{[7]}$. Above all, technology has contributed to human happiness. Similarly, Rodee e.tal contend that:

Science and technology had brought vast changes in agriculture, amusements, communications, economics, education, environments, labour and management, transportation, uses of the oceans and indeed, all aspects of modern life...effective exploitation of outer space and its natural resources, the production of enough food to meet the needs of constantly expanding population $^{[15]}$.

This implies that technology is the bedrock of civilization. This is manifested in the art of empowering people through all sorts of skills acquisition programmes. Furthermore, with the invention of all kinds of machines, technology provides economic empowerment, thereby eliminating poverty and joblessness. 
Reflecting upon the gruesome threats posed by science and technology, the gas sector constitutes the most invisible danger. What readily comes to mind here is chemical weapon, which is capable of wiping off the entire human race within few minutes. In recent decades, claims of the perceived use of chemical weapons (biological and toxin) had been reported ${ }^{[16]}$. The case in mind was the U.S / Iraqi's war. Going by the risk of loss of lives associated with biological and chemical weapons, there is the need to exercise restraint from further production and in using them. The international community should circumvent this unwholesome act through instituting legal constraints with grave penalty for countries and individuals that violate them. Greater attention must be focused on the control of chemical and biological weapons as they constitute a threat to world peace (security of lives and properties). What then is the essence of the application of scientific knowledge that is capable of annihilating the entire humanity throughout the surface of the earth? The point being emphasized here is that there is serious need for control as the use of chemical and biological weapons and the injuries they cause are somehow heinous. Take for instance, development in science and technology had made it possible for Nigeria to put in place refineries for the exploitation of its crude oil particularly around the Niger Delta region. This had resulted in unending crises as a result of chemical pollution and water hyacinth on the waterways. The inhabitants who are predominantly fishermen can no longer carry-on with their daily fish hunting because the polluted water is no longer habitable for fishes. Worst still, they no longer have access to portable water. The few farmers have no farmland owing to industrial pollution and chemical toxin on their land. Government's high level of insensitivity to their plights is responsible for the on-going crises in the Niger Delta. This study intends to show that a stitch in time saves nine. There are other areas of our national life where government policies need to address the deleterious consequences of development in science and technology to avert similar uprising like that of the Niger Delta.

Fasoranti examines the implication of the disposal of radioactive waste as an aspect of nuclear technology. The energy released by fusion nuclear explosives is more powerful than explosive such as dynamite. He, therefore, warns that:

A brief war fought with nuclear weapons might involve more destruction of lives and properties than all the previous wars of mankind and there is at least a theoretical possibility that such a war would lead to the extinction of life by poisoning the atmosphere with radio active particles ${ }^{[17]}$.

Ali maintains the view that the most serious ill effects of modern technology is the loss of man's spiritual values. It is his beliefs that:

- Environmental pollution, population problem and the overall technological discoveries of machines and other artifacts and

- the craze for the acquisition of them as well as the need to enhance this technological advancement have led to the loss of

- the spiritual part of homo sapiens, then only ontological thing which places man in a class higher than the lower primates. The natural treasure of peace, environmental bliss and quite have long been lost especially in the technological countries due to the multifarious noises arising from the churning of the factory wheels, the running of the innumerable, motor vehicles and allied automobiles, the zooming of air craft in the sky - as well as the blaring of the radio and television sets ${ }^{[11]}$.

The crux of the matter is that technology should not be allowed to foster at the detriment of life. Despite the fact that the society had been grossly polluted, Ali is of the opinion that the human brain must not be allowed to suffer or turned to robots. Hence, it was suggested that technological civilization must not be blindly embraced. There is the need to cultivate a cultural base endowed with rational framework, scientific outlook and ethical consideration ${ }^{[11]}$. To achieve this requires scientific and technological literacy through the establishment of suitable infrastructures and institutional arrangements. Manufacturers of various technologies must put in place necessary mechanisms for curtailing the foreseeable consequences of their products.

The rising tide of the phenomenon of globalization in the 21 st century has given impetus to the rapid development of information technology. The whole world is now being turned into a global village. Distance is no longer a barrier to communication. One of the major fallouts of these globalizing impacts of information technology is the emergence of the launching of satellite into the orbit. For instance, Nigeria communication satellite!

(NIGCOMSAT 1) was launched on 15th May, 2007 in far away China. 
It was reported that China Great Industry Corporation-a Chinese company designed, built and launched the satellite on behalf of Nigeria. The Nigeria communication satellite is expected to increase local telecommunication growth rate to an annual minimum of $13.5 \%$. It is also expected to complement existing satellite and networks thereby enhancing the growth of the industrial, commercial and administrative sectors of Nigerian economy ${ }^{[18]}$. The impacts of this satellite technology had received great attention by scholars. Ehinmore affirms that:

The launching of the satellite into the orbit has its own disadvantages, some of which are erosion of privacy as a result of internet facilities, the effect of radio active waves on man and the environment and some other social disorders like fraud and robbery. The moral decadence of youths in the $21^{\text {st }}$ century is also a product of satellite being launched since it makes the internet pornography possible. The books, magazines, films, photograph pictures and so on, which show sexual acts and images cause sexual excitement on adults and among couples in Nigeria $^{[19]}$.

The impacts of satellite technology are innumerable. We will only discuss the most notorious ones among them. The problem is how to control information technology given the nature of Internet browsing and access.

Fraudsters are capitalizing on investment opportunities afforded by Internet facilities across the globe. The youths are the culprits who are usually branded yahoo-yahoo boys and girls. They play all sorts of tricks on big corporations, business organisations and private individuals and get them defrauded under the pretence of doing business with them. The situation in Nigeria is getting more precarious as banks and many business organisations are already transacting on- line business. This on-line facility enables fraudsters to have access to such designated accounts. The problem therefore, with on-line business is erosion of privacy.

There is need for effective control mechanism if the gains from internet facilities such as timely and effective service delivery, eradication of the burden of carrying huge amount of money on roads at the mercy of car snatchers and armed robbers, are to be maximized. Indeed, we cannot do without science and technology because they enhance development. But what technologists need to do is to create subsidiary technology through which to detect foul play on the Internet.

\section{CONCLUSION}

The central problem addressed in this study has been the dynamic impact of scientific-technological change upon the individuals and societies in Africa with particular focus on Nigeria. The study shows that science and technology have changed lives in many significant respects, which had manifested in improved material conditions of life measured in terms of a standard of living. This phenomenon had culminated in serious demand for social and political change, which in turn has made the responsibilities of governments in Africa more significant than ever before. The direct consequences of having these social and political changes include problems of human security, escalation in crime wave and other forms of violent behaviours, problem of environmental pollution and protection and resource control which is the major cause of the ongoing Niger Delta crises in Nigeria.

The research therefore, suggests that greater attention must be focused on the control of chemical and biological weapons, as they constitute a threat to world peace. What then is the essence of the application of scientific knowledge that is capable of annihilating the entire humanity throughout the surface of the earth? The point being emphasized here is that there is serious need for control as the use of chemical and biological weapons and the injuries they cause are somehow heinous. Technology should not be allowed to foster at the detriment of life. To achieve this requires scientific and technological literacy through the establishment of suitable infrastructures and institutional arrangements. The Nigerian government should educate the public on the danger of erecting residential buildings along high voltage power lines and put in place legal instrument by which defaulters are to be disciplined. Manufacturers of various technologies must create subsidiary technology and put in place necessary mechanisms for curtailing the foreseeable consequences of their products.

Technological civilization must not be blindly embraced. There is the need to cultivate a cultural base endowed with rational framework and ethical consideration in some areas of our national life where government policies need to address the deleterious consequences of development in science and technology. Industrial pollution, chemical toxin and water hyacinth on the water ways to be urgently addressed in Nigeria to avert the on-going Niger Delta crises and to forestall similar uprising in other oil producing regions in the country. Furthermore, the 
government needs to put in place mechanism for identifying foul play and sharp practices on the internet.

Above all, the situation in Nigeria as presented in this study is a replica of what obtains in the whole of the African continent.

\section{REFERENCES}

1. Awake, March 8, 1998. pp: 3-12.

2. The Punch, February 28, 2008. p: 16

3. Russell, B., 1962. The Scientific Outlook. W.W. Norton and Company, New York, pp: 62.

4. Nagel, E., 1961. The Structure of Science. Harcourt Bruce and World Inc, New York, pp: 1-3.

5. Morgan, R., 1979. Science and Technology for Development: The Role of U.S University, Pergamon Press, New York, pp: 18.

6. Smith, T.M., 1967. Technology. In: New Catholic Encyclopedia, Catholic University of America Press, Washington, pp: 967.

7. Fadahunsi, A., 2003. Philosophy, Science and Technology. Hope Publications Ibadan, pp: 16-23, 36-42.

8. Onuobia, O.N., 1991. History and Philosophy of Science. Maiden Educational Publishers Ltd, Aba, pp: 185-186.

9. Asimor, I., 1975. Biographical Encyclopedia of Science and Technology. Chaucer Press Ltd, Britain, pp: 232.
10. Goldsmith, M., 1986. The Science Critic. Routledge and Kegan Paul, New York, pp: 11-12.

11. Ali, A., 2003. Culture, Technology and Society. In: Philosophy, Science and Technology, Fadahunsi, A. (Ed.)., Hope Publications, Ibadan, pp: 16-23, 36-42, 100, 102.

12. Bryan, S.T., 1987. State, Science and Economy in Traditional Society: Some Problems in Weberian Sociology of Science. Br. J. Sociol., 38: 13-20.

13. Dickson, D., 1979. Science and political hegemony in the 17 th century. Radical Sci. J., 8: 7-37.

14. Olaolu, M., 2003. Technology and Human Happiness: An Evaluation. In: Philosophy, Science and Technology, Fadahunsi, A. (Ed.). Hope Publications, Ibadan, pp: 58-64.

15. Rodee, C.C., T.J. Anderson, C.Q. Christol and T.H. Greene, 1983. Introduction to Political Science. McGraw Hill International Book Company, Japan, pp: 245.

16. Leshuk, L., 2002. A More Insidious Enemy. Europa University Press, Washington, D.C., pp: $120-151$.

17. Fasoranti, O.O., 2004. Understanding Sociology. Lagos University Publishing Inc., pp: 272.

18. The Punch, May 8, 2007. p: 24

19. Ehinmore, O.M., 2007 Indigenous nigerian family system in Era of globalization: A historical survey. J. Applied Philosophy., 1: 78. 